\title{
Asaccular aneurysm of the ascending aorta following coronary artery bypass graft surgery
}

\begin{abstract}
The saccular aneurysms of the ascending aorta are rarely seenand are usually lifethreatening.There are a few reports for saccular ascending aortica neurysm which are following coronary artery bypass graft surgery. Open surgical repair of the saccular aneurysm of the ascending aorta has highrisks and mortality rate. The saccular aneurysms of the ascending aorta are more prone to rupture, for this reason repair at smaller diameters is recommended when diagnosed.
\end{abstract}

Keywords: saccular aneurysm, ascending aorta, coronary artery, bypass graftsurgery

\author{
Volume 3 Issue 4 - 2016
}

\author{
Serkan Burc Deser, Mustafa Kemal Demirag \\ Department of Cardiovascular Surgery, Ondokuz Mayis \\ University, Turkey
}

\begin{abstract}
Correspondence: Serkan Burc Deser, Department of Cardiovascular Surgery, Ondokuz Mayis University, Faculty of Medicine, 55139 Samsun, Turkey, GSM 009053850 I 2010, Fax 00903624576091,Email sbd983@yahoo.com
\end{abstract}

Received: September 18,2016 | Published: September 28, 2016

\section{Introduction}

An aneurysm is defined as dilatation of the artery greater than $50 \%$ in diameter. Aneurysms are categorized as fusiform or saccular. The saccular aneurysms of the ascending aorta are rarely seen and are usually life-threatening. Excessive use of biologicglue, graft infection, mediastinitis, aortic dissection, atherosclerosis, hypertension, degeneration of a penetrating atherosclerotic ulcer, poorsurgical technique, trauma, fungal infections and previous aortic surgery (presumably due to the cannulation site) are the etiologic risk factors for the development of a false or true aneurysm of the ascending aorta. ${ }^{1}$ There are a few reports for saccular aneurysm of the ascending aorta which are following coronary artery bypass grafting surgery. The wall stressis greater in saccular aneurysms rather than fusiform aneurysms. The disruption of the vesse lwall at the cannulation site oral long the aortic suture lines lead to saccular aneurysm.

Theaortic false aneurysm may surrounded and restricted by the layers or structures of themediastinum. ${ }^{2}$ The clinical presentation of a false aneurysms of the ascending aorta are persistent infection and systemic embolization, bleeding, fistula, compression, orerosion of the surrounding structures. Open surgical repair of the saccular aneurysm of the ascending aorta has highrisks and mortality rate (ranges between $6.9 \%$ and $15.4 \%$ ). ${ }^{3}$ The saccular aneurysms of the ascending aorta are more prone to rupture, for this reason repair at smaller diameters is recommended when diagnosed. Usually ruptures into the pleural cavity. Some authors proposed that surgical repair is the only reasonable option. Aneurysm repair wasrecommended for all saccular aneurysms of the ascending aorta regardless of size or symptoms.

\section{Case report}

A 61-year-old female was presented with hypertension, dyslipidemia and diabetes. She had a history of coronary artery bypass grafting surgery 8 years ago. She did not have anycomplaint. Chest $\mathrm{X}$-ray showed minimal enlargement of the cardiacsilhouette. On physical examination no pathology finding was found. A $15 \times 15 \mathrm{~mm}$ sacculara neurysmon the ascending aorta was revealed on computed to mograhy $(\mathrm{CT})$ on routineannually scanning which was presumably originate from the cannulation site (Figure 1). The patient's EuroSCORE was 9. Cardiac functions were normal upon transthoracicecho cardiographic examination. We suggested open surgery for this saccular aneurysm on the ascending aorta however, she did not accept. The patient was following up with CT scan quarterly.

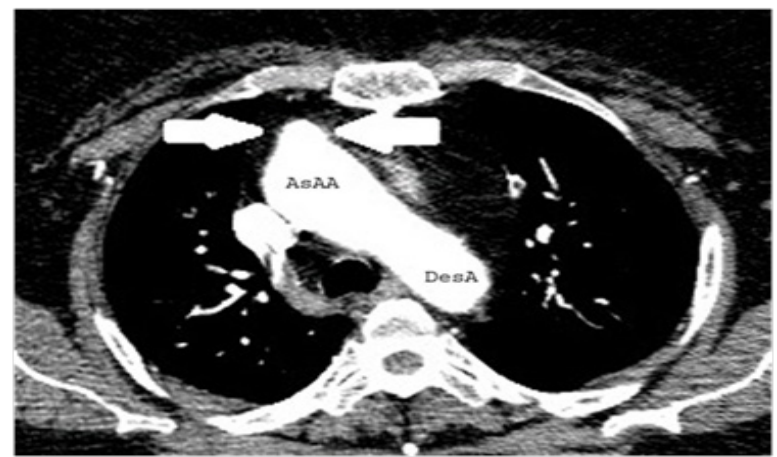

Figure I View of the $15 \times 15 \mathrm{~mm}$ saccularaneurysm on the ascending aorta on the computed to mograhy $(\mathrm{CT})$ (White arrow). Ascending aorta (AsAA) Descending aorta (DeA).

\section{Discussion and conclusion}

A saccular aneurysm on the ascending aorta can be a complication of the cardiopulmonary bypass grafting surgery further more, reoperation is challenging and is becoming a more frequent diagnosis. Most of the patients were asymptomatic at the time of diagnosis. The saccular aneurysm on the ascending aorta should be treated regard less of etiology even if asymptomatic. ${ }^{4}$ The most common complaints are chestpain, heart failure, sepsis ortracheal compression. Both clinical and radiologic follow-up is essential. The saccular aneurysm of the ascending aorta has a high risk of rupture. There are several treatment options. Open surgery with aortic graft replacement has $6.9-15.4 \%$ in hospital mortality. ${ }^{3}$ Thrombin embolization or coiling may lead to cerebral embolization or migration. Septaloccluder devices can also be used however, no good long-term outcomes have been as certained. ${ }^{5}$ Thoracic Endovascular Aortic Repair (TEVAR) 
can be used endovascular technique with satisfactory results and can be used to treat all types of saccularaneurysm of the ascending aorta. The curvature of the arcusaorta, the distance between the sino tubular junction and the branches of the arcus aorta, adjacencyto the coronaryarteries, competency of the aortic valve are essential for the TEVAR. Hybrid repair can be used to maintain the patency of the branches of the arcus aorta however, extra anatomic by passes are required. ${ }^{6}$ Despite advances in endovascular techniques open surgery remains the treatment of choise. Debridement of allnecrotic an dinfected tissue is essential to avoid the recurrence of the false aneurysm.

\section{Acknowledgements}

None.

\section{Conflict of interest}

The author declares no conflict of interest.

\section{References}

1. Erdal C, Celik S, Baykan M. A saccularaneurysm on the ascending aorta following aortic valve replacement. Int J Cardiol. 2001;79(2-3):263-264.

2. Malvindi PG, Van Putte BP, Heijmen RH, et al. Reoperations for aortic false aneurysms after cardiac surgery. Ann Thorac Surg. 2010;90(5):14371443 .

3. Eusanio DM, Berretta P, Bissoni L, et al. Re-operations on the proximal thoracic aorta: results and predictors of short- and long-term mortality in a series of 174 patients. Eur J Cardiothorac Surg. 2011;40(5):1072-1076.

4. Piffaretti G, Cottini M, Carrafiello G, et al. Endovascular repair of ascending aortic pseudo aneurysm with custom-designed endograft. Ann Thorac Surg. 2015;100(2):31-33.

5. Powell JT, Sweeting MJ, Brown LC, et al. Systematic review and metaanalysis of growth rates of small abdominal aortic aneurysms. Br J Surg. 2011;98(5):609-618.

6. Shang EK, Nathan DP, Boonn WW, et al. A modern experience with saccular aortic Aneurysms. J Vasc Surg. 2013;57(1):84-88. 